\title{
Prognostic role of HSPs in human gastrointestinal cancer: a systematic review and meta-analysis
}

This article was published in the following Dove Press journal:

OncoTargets and Therapy

Hua Ge'

Yan Yan ${ }^{2}$

Lingfei Guo'

Fei Tian'

DiWu'

'Department of Gastrointestinal Surgery, ${ }^{2}$ Quality Control Department,

The First People's Hospital of Zunyi,

Zunyi Medical University, Huichuan,

Zunyi, Guizhou, China
Correspondence: Hua Ge

Department of Gastrointestinal Surgery,

The First People's Hospital of Zunyi,

Zunyi Medical University, No 98

Fenghuang Street, Huichuan, Zunyi

563000, Guizhou, China

Tel +86 I868523 7।I9

Email zyyyhuage@126.com
Background: Heat shock proteins (HSPs) have been reported to be overexpressed in a wide range of human tumors. It has been shown that HSPs act as an oncogenic regulator and are involved in tumorigenesis. The clinical and prognostic significance of HSPs in gastrointestinal cancers (GICs) remains controversial. The aim of this study was to conduct a meta-analysis to assess the prognostic value of HSPs in GICs.

Materials and methods: A literature search was performed in PubMed, Cochrane Library, Web of Science, and Embase databases. Data on the relationship between expression of HSPs and survival outcomes were extracted. Pooled hazard ratios (HRs) with 95\% CI were calculated.

Results: The expression of HSPs was not associated with the overall survival (OS) of GIC patients; however, it was significantly associated with worse OS for gastric cancer (GC) and colorectal cancer (CRC) patients.

Conclusion: Current evidence suggests that a high level of HSPs may not be a potential marker to predict the survival rate for every type of GICs. However, the expression of HSPs may predict a poor prognosis for $\mathrm{GC}$ and $\mathrm{CRC}$ patients.

Keywords: heat shock protein, gastrointestinal cancer, prognosis, meta-analysis

\section{Background}

Gastrointestinal cancers (GICs) are the most frequently diagnosed cancers of the digestive tract system and are the leading cause of cancer death in men and women worldwide. ${ }^{1,2}$ Esophageal cancer (EC), gastric cancer (GC), colorectal cancer (CRC), pancreatic cancer (PC), hepatocellular carcinoma (HCC), and gallbladder carcinoma (GBC) are the major malignancies of GICs. It has been reported that GICs account for $30 \%$ of the global incidence and $40 \%$ of the global malignant tumor mortality. ${ }^{3}$ $\mathrm{CRC}$ and HCC are the third and fifth most frequent cancers, whereas EC and GC are relatively rare but have poorer prognosis, with $18.4 \%$ and $30.4 \% 5$-year survival rate in the USA, respectively. ${ }^{2,4} \mathrm{GBC}$ is a rare gastrointestinal malignancy, but it is the most common malignant tumor of the biliary tract worldwide. ${ }^{5,6}$ Although progression has been made in tumor diagnosis and treatment, the clinical outcome of GICs remains disappointed. This is generally because there is still a lack of effective early diagnosis methods, and most GIC patients develop cancer into an advanced stage at the time of diagnosis. Therefore, prognostic and predictive factors are urgently needed for cancer patients to guide clinical decision.

Heat shock proteins (HSPs) are a set of highly conserved proteins, which were first discovered as stress-inducible proteins. ${ }^{7}$ Under physiological conditions, HSPs are expressed at low levels and function as molecular chaperones that mediate cell 
growth, apoptosis, protein homeostasis, and cellular targets of peptides. ${ }^{8}$ HSPs have been classified into various subfamilies according to their molecular weight or systematic gene symbols. ${ }^{9}, 10$ Broadly, the main HSPs are currently classified into five families, including HSP110, HSP90, HSP70, HSP60, and the small HSPs. ${ }^{11}$ Aberrant expression of HSPs has been reported in a wide range of human tumors, including breast, endometrial, ovarian, colon, lung, and prostate tumors. ${ }^{12}$ Recent studies have shown that the expression of HSPs is closely related to prognosis of cancers. The aim of this paper was to more precisely estimate the relationship between expression of multiple HSPs and prognosis of patients and investigate the possible utility of HSPs as prognostic biomarkers in GIC patients.

\section{Materials and methods}

\section{Search strategy and study selection}

The literature relevant to expression of HSPs and survival in gastrointestinal tumors were searched in PubMed, Cochrane Library, Web of Science, and Embase databases. The search ended in October 1, 2017. The search terms included the following keywords in various combinations: heat shock protein, HSP, stress protein, esophageal neoplasms, stomach neoplasms, colorectal neoplasms, hepatocellular neoplasms, pancreatic neoplasms, and gallbladder cancer. The references list of included studies and reviews was further sifted to identify additional potentially relevant studies.

To be eligible for inclusion in this meta-analysis, studies were required to meet the following criteria: 1) the study was published in English with the full text available; 2) studies focused on GICs, including human primary $\mathrm{EC}, \mathrm{GC}, \mathrm{CRC}$, $\mathrm{HCC}, \mathrm{PC}$, and GBC; 3 ) the definition of HSP positive was tested by immunohistochemistry (IHC); 4) HSPs as prognostic markers were used to predict the prognosis for cancer patients; and 5) studies provided hazard ratio (HR) and 95\% CI or Kaplan-Meier survival curves with sufficient data to extract HRs and 95\% CI.

The exclusion criteria for this study were as follows: 1) laboratory articles, reviews, case reports, conference abstracts, and letters; 2) nonhuman subject studies; 3) overlapping articles or ones with duplicate data; and 4) no data on survival or unable to calculate HRs based on data provided.

\section{Data extraction and quality assessment}

Two investigators searched and assessed the studies independently. Extracted data included first author's name, publication year, number of patients, region, type of cancer, cutoff value, follow-up time, and HRs with 95\% CI for overall survival (OS). If the data extraction results were inconsistent, third-party adjudication was consulted to reach a consensus.

Newcastle-Ottawa Scale (NOS) was adopted to assess the quality of included studies. We regarded the study with an NOS score of $\geq 6$ as of good quality, and the study with $\leq 5$ score was considered as of poor quality. Studies considered to be of high quality were included in this meta-analysis.

\section{Statistical analysis}

Statistical analysis was performed using RevMan 5.3 and Stata 12.0 software. Pooled estimates of HRs and 95\% CI were used to evaluate the association between expression of HSPs and OS. The heterogeneity between studies was evaluated by $\chi^{2}$ and $I^{2}$ test. When the result $\left(I^{2}>50 \%\right.$ or $\left.p<0.05\right)$ indicated heterogeneity, the random-effects model was used for the meta-analysis. Otherwise, a fixed-effects model was used. The software Engauge Digitizer was used to extract the survival data from a Kaplan-Meier curve in some articles. HR $>1$ implied a worse prognosis for the group with positive HSP expression and would be considered to be statistically significant if the 95\% CI did not overlap 1. Publication bias was examined by the Begg's funnel plot test.

\section{Results}

\section{Study identification and characteristics}

As shown by the search flow diagram (Figure 1), 24 studies (six EC, seven GC, four CRC, three PC, three HCC, and one GBC) involving a total of 3,413 patients (581 with EC, 1,453 with GC, 811 with CRC, 210 with PC, 251 with HCC, and 107 with GBC) were included in our meta-analysis based on selection criteria. ${ }^{13-36}$ The included studies were published from 1999 to 2017, and sample sizes ranged from 41 to 458 patients. More than half of included studies were from East Asian countries. All of included studies received scores $\geq 6$ in methodological assessments, which meant they had high quality. Characteristics of included studies are summarized in Table 1.

\section{Meta-analysis}

In this study, we evaluated the correlation between expression of HSPs and OS time of patients with GICs. As shown in Figure 2, combining all included studies, expression of HSPs was not associated with the OS of GIC patients $(\mathrm{HR}=1.17,95 \% \mathrm{CI}=[0.90,1.52], p=0.25)$. However, the expression of HSPs was significantly associated with worse OS of $\mathrm{GC}(\mathrm{HR}=1.63,95 \% \mathrm{CI}=[1.03,2.57], p=0.04)$ and $\mathrm{CRC}(\mathrm{HR}=1.67,95 \% \mathrm{CI}=[1.25,2.24], p=0.0006)$ patients. 


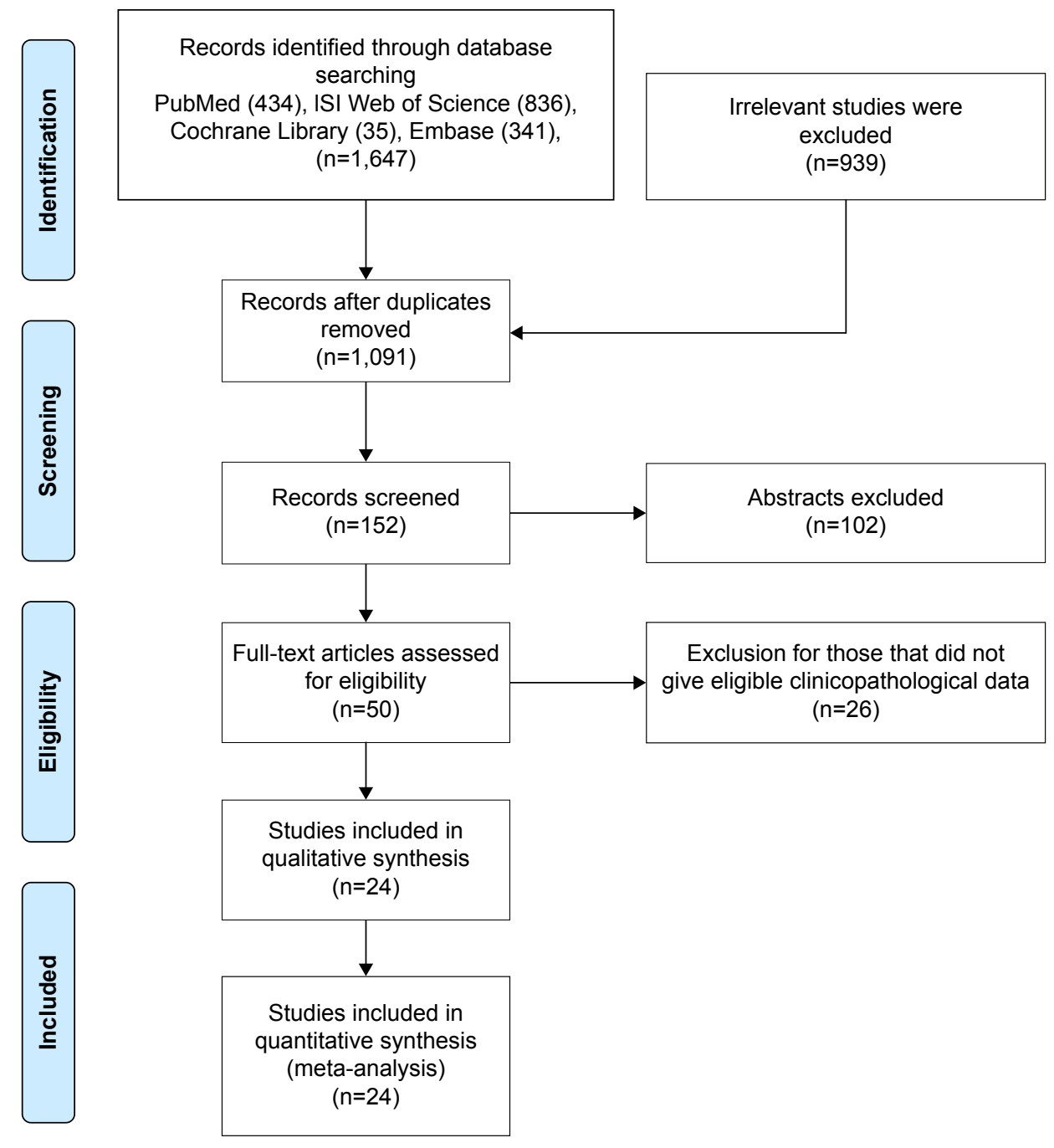

Figure I Flow diagram of study selection.

The pooled HRs of HSP27, HSP60, HSP70, and HSP90 showed that the expression of these HSPs could not act as an effective prognostic marker in GICs (Figure 3).

\section{Subgroup analysis}

Subgroup analysis was performed on sample size, NOS score, and cutoff value to explore potential sources of heterogeneity. As seen in Table 2, when samples were divided into subgroups, expression of HSPs was correlated with OS in the bigger sample size subgroup $(\mathrm{n}>110$; $\mathrm{HR}=1.46,95 \% \mathrm{CI}=$ $[1.09,1.94], p=0.01)$. However, there was heterogeneity of expression of HSPs in both the bigger and the small sample size subgroups. NOS score of studies did not influence the relationship between HSPs and OS. Again, there was heterogeneity in both subgroups. Additionally, when divided by cutoff values, there was no heterogeneity in the not reported group.

\section{Publication bias and sensitivity analysis}

Begg's funnel plot was performed to evaluate publication bias. The funnel plot of the selected studies showed significant symmetry (Figure 4A). Sensitivity analysis indicated that no point estimate of the omitted individual dataset lay outside the $95 \% \mathrm{CI}$ of the combined analysis based on the overall HR estimate of OS (Figure 4B). Thus, the results of this meta-analysis were reliable.

\section{Discussion}

HSPs are a class of proteins that are ubiquitously distributed in organisms from prokaryotic organisms to eukaryotic organisms. HSPs were shown to be overexpressed in a broad range of tumors, and the expression of HSPs has been associated with tumor cell proliferation and differentiation, as well as with resistance to apoptosis and poor prognosis. ${ }^{12,37}$ Tumorigenesis is a complicated process involving a variety of mutation 


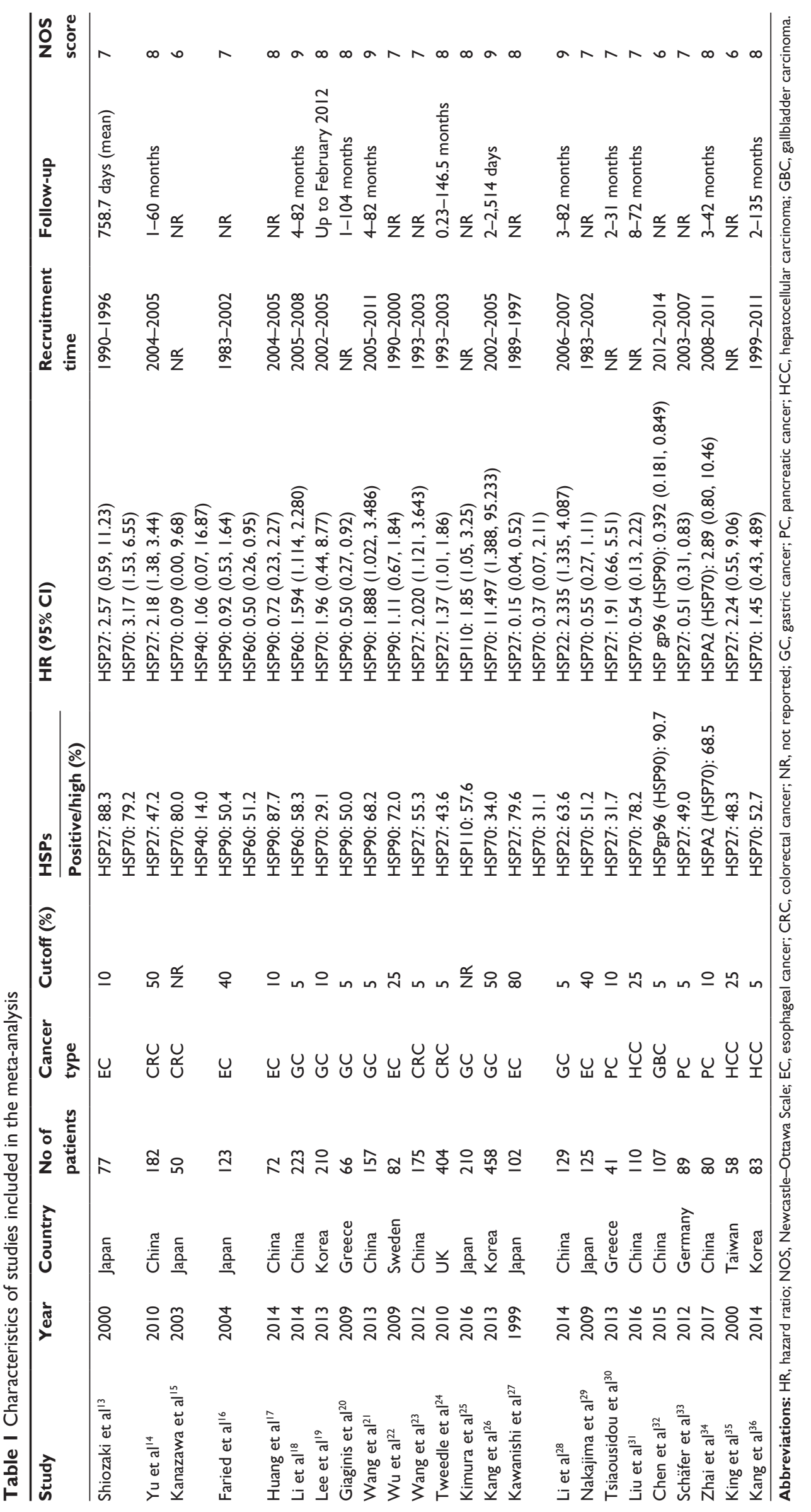




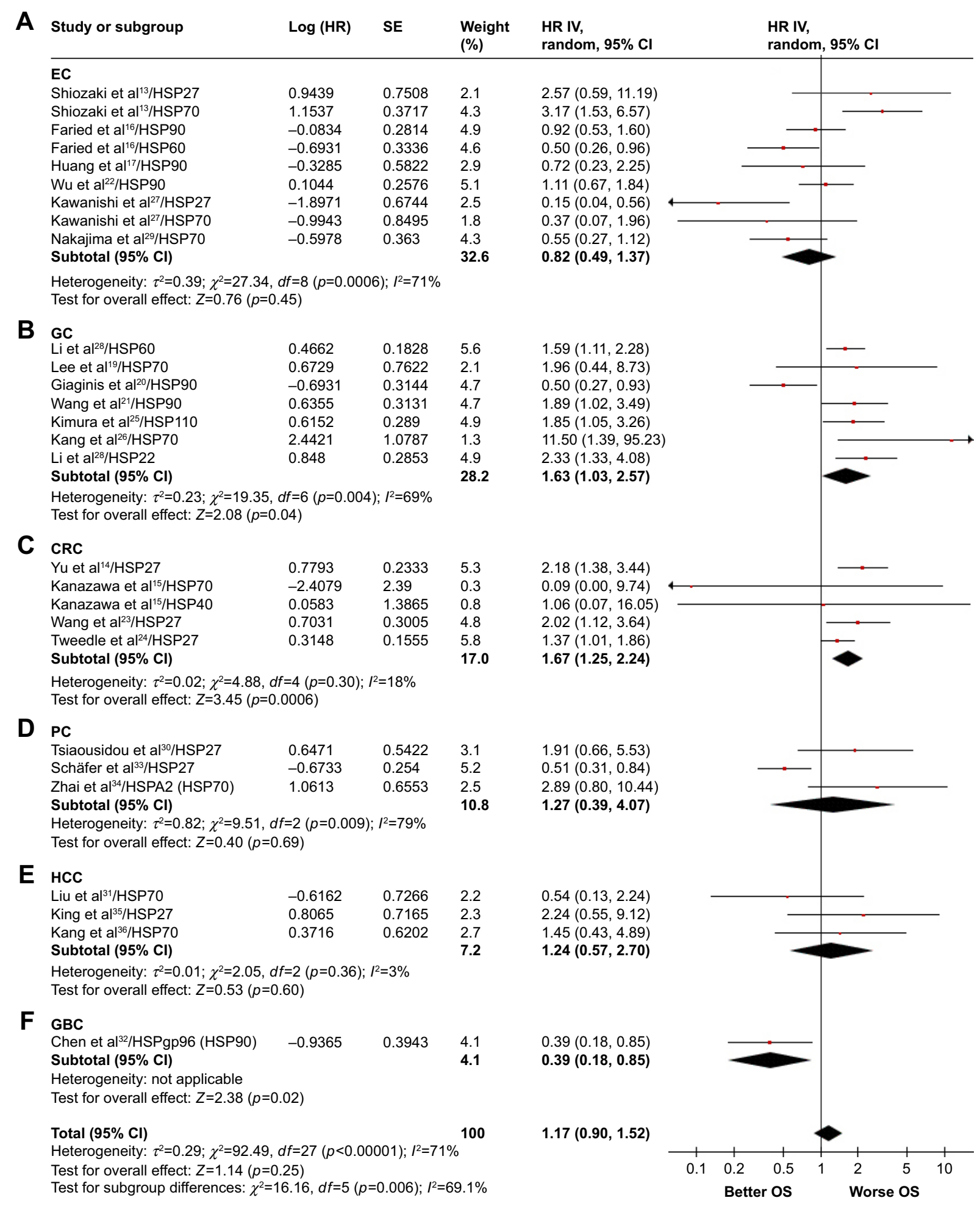

Figure 2 Forest plot of OS associated with the expression level of different HSPs in GIC patients.

Notes: (A) Specific expression of HSPs in EC. (B) Specific expression of HSPs in GC. (C) Specific expression of HSPs in CRC. (D) Specific expression of HSP in PC. (E) Specific expression of HSPs in HCC. (F) Specific expression of HSPs in GBC.

Abbreviations: OS, overall survival; GIC, gastrointestinal cancer; EC, esophageal cancer; GC, gastric cancer; CRC, colorectal cancer; PC, pancreatic cancer; HCC, hepatocellular carcinoma; GBC, gallbladder carcinoma; HR, hazard ratio; SE, standard error; IV, intravenous.

accumulation. As molecular chaperone, HSPs participate in the functional metabolism of tumor cells and protect tumor cells from harmful factors in the process of tumor formation. ${ }^{38}$ Certain HSPs can provide an immunogenic context to peptides that associate with them inside tumor or infected cells, which induces specific cytotoxic T-cell responses and protective immunity. ${ }^{39}$ Meanwhile, HSPs allow tumor cells to tolerate genetic alterations, which would otherwise be fatal. ${ }^{40}$ 


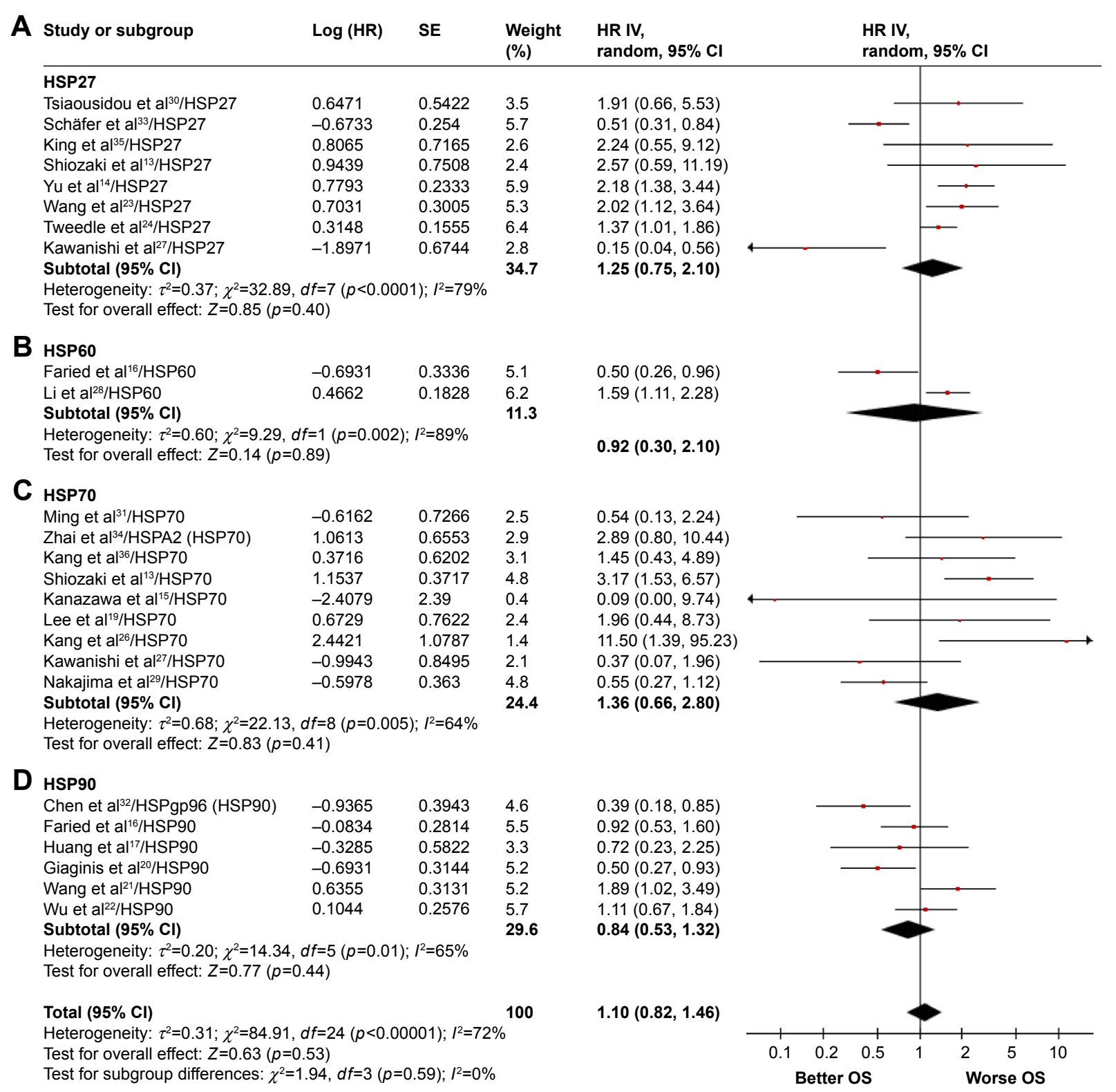

Figure 3 Forest plot of OS associated with specific HSPs in GIC patients.

Notes: (A) HSP27 expression in GICs. (B) HSP60 expression in GICs. (C) HSP70 expression in GICs. (D) HSP90 expression in GICs.

Abbreviations: OS, overall survival; GIC, gastrointestinal cancer; HR, hazard ratio; SE, standard error; IV, intravenous.

Table 2 Subgroup analysis of OS

\begin{tabular}{|c|c|c|c|c|c|c|}
\hline Subgroups & $\begin{array}{l}\text { No of } \\
\text { studies }\end{array}$ & $\begin{array}{l}\text { No of } \\
\text { patients }\end{array}$ & $\begin{array}{l}\text { Pooled HR } \\
(95 \% \mathrm{Cl})\end{array}$ & PHet & $I^{2}(\%)$ & $p$-value \\
\hline \multicolumn{7}{|l|}{ Sample size } \\
\hline$\leq 110$ & 13 & 1,017 & $0.90(0.58,1.40)$ & 0.0001 & 66.0 & 0.64 \\
\hline$>110$ & 11 & 2,396 & $1.46(1.09,1.94)$ & 0.0006 & 66.0 & 0.01 \\
\hline \multicolumn{7}{|l|}{ NOS score } \\
\hline$\leq 7$ & 11 & $\mathrm{I}, 037$ & $0.99(0.66, I .47)$ & 0.0001 & 68.0 & 0.94 \\
\hline$>7$ & 13 & 2,376 & $1.38(0.99,1.93)$ & 0.0002 & 67.0 & 0.05 \\
\hline \multicolumn{7}{|l|}{ Cutoff } \\
\hline$\leq 10 \%$ & 14 & 1,913 & I.34 $(0.96$, I.87) & $<0.00001$ & 73.0 & 0.09 \\
\hline$>10 \%$ & 8 & 1,240 & $0.87(0.52$, I.47) & $<0.00001$ & 74.0 & $0.6 \mathrm{I}$ \\
\hline NR & 2 & 260 & $1.73(1.00,3.01)$ & 0.43 & 0.0 & 0.05 \\
\hline
\end{tabular}

Abbreviations: OS, overall survival; HR, hazard ratio; NOS, Newcastle-Ottawa Scale; NR, not reported. 


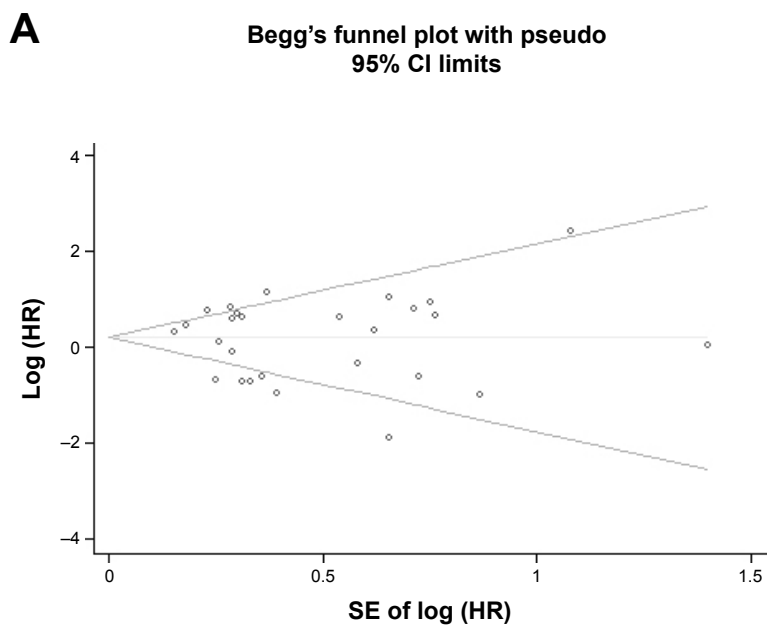

Figure 4 Publication bias and sensitivity analysis.

Notes: (A) Begg's publication bias plot. (B) Chart of sensitivity analysis.

Abbreviations: SE, standard error; HR, hazard ratio.

GIC is one of the major health care problems in the world. Clinical parameters such as lymph node metastasis and TNM stage are generally considered as prognostic factors but are insufficient to provide useful information for clinical management. The expression of HSPs likely provides a crucial function in tumorigenesis and tumor invasion. However, the clinical evidence for this role of HSPs in GICs was inconclusive. Thus, we performed this meta-analysis to explore the prognostic value of HSPs for GICs.

In this study, we included 24 studies about the prognostic value of HSPs in GICs. The results suggested that positive expression of HSPs was not significantly correlated with OS for GICs. However, we found that the expression of HSPs was significantly associated with poor OS in GC and CRC patients.

Various molecular mechanisms involved in the carcinogenesis of HSPs have been investigated. Enhanced expression of HSPs during the progression of cancer cells implies its close relationship with the cell growth. ${ }^{41}$ In GC, blocking HSP90 disrupts EGFR, HER-2, and HIF-1A signaling pathways and inhibits cell proliferation in vitro and in vivo. ${ }^{42,43}$ It has been reported that HSP60 regulates apoptosis by direct interaction with cyclophilin D in the mitochondrial permeability transition pore, which reduces caspase-dependent apoptosis. ${ }^{44}$ A Phase II study of the tumor vaccine with HSPPC-96 reported that GC patients who received the vaccine had improved disease-free survival, and the 2-year OS rates were $81.9 \%$ and $67.9 \%$ for the gp96 vaccination and chemotherapy alone group, respectively. ${ }^{45}$ Expression of HSP27 in CRC cells enhances their apoptotic resistance in vitro and significantly increases their tumorigenicity
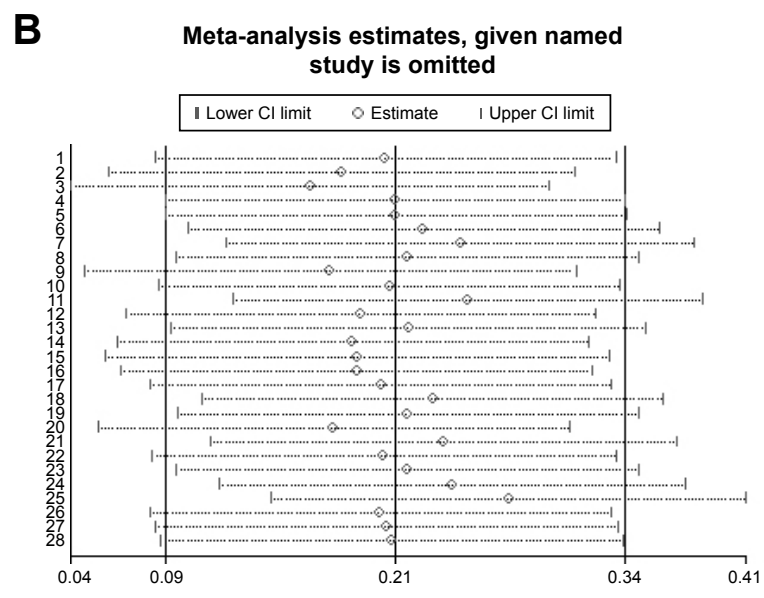

in vivo. ${ }^{46} \mathrm{HSP} 27$ is constitutively activated in $\mathrm{CD} 133^{+} \mathrm{CRC}$ stem cells, and HSP27 activation is required in $\mathrm{CD} 133^{+}$ cells to prevent caspase- 3 and caspase- 9 cleavages in the apoptosis cascade. Inhibition of Hsp27 signaling sensitizes $\mathrm{CD} 133^{+}$cells to hypoxia and serum depletion-induced apoptosis. ${ }^{47}$ Hwang et $\mathrm{al}^{48}$ reported that compared with weakly metastatic colorectal cell lines, HSP70 expression was elevated in the highly metastatic cell line and HSP40 is colocalized with HSP70 in the nuclei and nucleoli of mammalian cells, where it interacts and cooperates with HSP70. ${ }^{49}$ HSP inhibitors can reduce the malignant biological function of tumor cells. ${ }^{50}$ In preclinical experiments, ganetespib has been shown to downregulate several HSP90 client proteins in CRC cells and lead to potent anticancer activity in vitro and in vivo. ${ }^{51,52}$ Together, these studies indicate that HSPs have a significant impact on prognosis of $\mathrm{GC}$ and $\mathrm{CRC}$, which is consistent with our findings.

In this meta-analysis, there is significant heterogeneity in the analysis of prognostic value of HSPs. Although we conducted subgroup analysis and sensitivity analysis, the source of heterogeneity has not been fully explained. However, heterogeneity may be produced in the following aspects. First, all the included studies tested the expression of HSPs by IHC, differences in reagent and staining protocols, which may lead to a potential bias. Second, the cutoff value defining a section with positive HSP expression among the included studies is different, which also might produce heterogeneity. Third, due to the unified follow-up time, heterogeneity may be virtually brought in. Fourth, different types of cancers and inherent molecular differences might increase the heterogeneity. As eligible articles for meta-analysis were 
limited, more studies are still needed to provide more reliable evidence to evaluate the impact of expression of HSPs on clinical outcomes of GICs.

\section{Limitations}

Some limitations of our meta-analysis should be emphasized. First, only English literatures were included, due to the reason that literatures published in other languages were not available. Second, the number of included studies was limited, and only one study with gallbladder cancer was included in this meta-analysis, which may lead to a less powerful result in this meta-analysis. Third, more than half of included studies were carried out in Asian population; hence, it might be insufficient to draw conclusions that can be applied to all ethnic groups.

\section{Conclusion}

Our meta-analysis suggests that a high level of HSPs may not be potential markers to predict survival rate for every type of GICs. However, expression of HSPs may predict a poor prognosis for $\mathrm{GC}$ and $\mathrm{CRC}$ patients. Owing to the limitations, additional studies related to tumor types are necessary to illuminate the clinical utility of increased HSPs in GICs.

\section{Disclosure}

The authors report no conflicts of interest in this work.

\section{References}

1. Torre LA, Bray F, Siegel RL, Ferlay J, Lortet-Tieulent J, Jemal A. Global cancer statistics, 2012. CA Cancer J Clin. 2015;65(2):87-108.

2. Jemal A, Bray F, Center MM, Ferlay J, Ward E, Forman D. Global cancer statistics. CA Cancer J Clin. 2011;61(2):69-90.

3. Rokavec M, Li H, Jiang L, Hermeking H. The p53/microRNA connection in gastrointestinal cancer. Clin Exp Gastroenterol. 2014;7: 395-413.

4. Howlader N, Noone AM, Krapcho M, et al. SEER Cancer Statistics Review, 1975-2013. Bethesda: National Cancer Institute; 2015.

5. Miller G, Jarnagin WR. Gallbladder carcinoma. Eur J Surg Oncol. 2008;34(3):306-312.

6. Alexander S, Lemmens VE, Houterman S, Nollen L, Roumen R, Slooter GD. Gallbladder cancer, a vanishing disease? Cancer Causes Control. 2012;23(10):1705-1709.

7. Lindquist S, Craig EA. The heat-shock proteins. Annu Rev Genet. 1988;22:631-677.

8. Morimoto RI. Cells in stress: transcriptional activation of heat shock genes. Science. 1993;259(5100):1409-1410.

9. Garrido C, Gurbuxani S, Ravagnan L, Kroemer G. Heat shock proteins: endogenous modulators of apoptotic cell death. Biochem Biophys Res Commun. 2001;286(3):433-442.

10. Kampinga HH, Hageman J, Vos MJ, et al. Guidelines for the nomenclature of the human heat shock proteins. Cell Stress Chaperones. 2009;14(1):105-111.

11. Westerheide SD, Morimoto RI. Heat shock response modulators as therapeutic tools for diseases of protein conformation. J Biol Chem. 2005;280(39):33097-33100.
12. Ciocca DR, Calderwood SK. Heat shock proteins in cancer: diagnostic, prognostic, predictive, and treatment implications. Cell Stress Chaperones. 2005;10(2):86-103.

13. Shiozaki H, Doki Y, Kawanishi K, et al. Clinical application of malignancy potential grading as a prognostic factor of human esophageal cancers. Surgery. 2000;127(5):552-561.

14. Yu Z, Zhi J, Peng X, Zhong X, Xu A. Clinical significance of HSP27 expression in colorectal cancer. Mol Med Rep. 2010;3(6):953-958.

15. Kanazawa $\mathrm{Y}$, Isomoto $\mathrm{H}, \mathrm{Oka} \mathrm{M}$, et al. Expression of heat shock protein (Hsp) 70 and Hsp 40 in colorectal cancer. Med Oncol. 2003;20(2): 157-164.

16. Faried A, Sohda M, Nakajima M, Miyazaki T, Kato H, Kuwano H. Expression of heat-shock protein Hsp60 correlated with the apoptotic index and patient prognosis in human oesophageal squamous cell carcinoma. Eur J Cancer. 2004;40(18):2804-2811.

17. Huang TY, Chen S, Han H, et al. Expression of Hsp90 $\alpha$ and cyclin B1 were related to prognosis of esophageal squamous cell carcinoma and keratin pearl formation. Int J Clin Exp Pathol. 2014;7(4):1544-1552.

18. Li XS, Xu Q, Fu XY, Luo WS. Heat shock protein 60 overexpression is associated with the progression and prognosis in gastric cancer. PLoS One. 2014;9(9):e107507.

19. Lee HW, Lee EH, Kim SH, Roh MS, Jung SB, Choi YC. Heat shock protein 70 (HSP70) expression is associated with poor prognosis in intestinal type gastric cancer. Virchows Arch. 2013;463(4):489-495.

20. Giaginis C, Daskalopoulou SS, Vgenopoulou S, Sfiniadakis I, Kouraklis G, Theocharis SE. Heat shock protein-27, -60 and -90 expression in gastric cancer: association with clinicopathological variables and patient survival. BMC Gastroenterol. 2009;9:14.

21. Wang J, Cui S, Zhang X, Wu Y, Tang H. High expression of heat shock protein 90 is associated with tumor aggressiveness and poor prognosis in patients with advanced gastric cancer. PLoS One. 2013;8(4):e62876.

22. Wu X, Wanders A, Wardega P, et al. Hsp90 is expressed and represents a therapeutic target in human oesophageal cancer using the inhibitor 17-allylamino-17-demethoxygeldanamycin. Br J Cancer. 2009; 100(2):334-343.

23. Wang F, Zhang P, Shi C, Yang Y, Qin H. Immunohistochemical detection of HSP27 and hnRNP K as prognostic and predictive biomarkers for colorectal cancer. Med Oncol. 2012;29(3):1780-1788.

24. Tweedle EM, Khattak I, Ang CW, et al. Low molecular weight heat shock protein HSP27 is a prognostic indicator in rectal cancer but not colon cancer. Gut. 2010;59(11):1501-1510.

25. Kimura A, Ogata K, Altan B, et al. Nuclear heat shock protein 110 expression is associated with poor prognosis and chemotherapy resistance in gastric cancer. Oncotarget. 2016;7(14):18415-18423.

26. Kang Y, Jung WY, Lee H, et al. Prognostic significance of heat shock protein 70 expression in early gastric carcinoma. Korean JPathol. 2013; 47(3):219-226.

27. Kawanishi K, Shiozaki H, Doki Y, et al. Prognostic significance of heat shock proteins 27 and 70 in patients with squamous cell carcinoma of the esophagus. Cancer. 1999;85(8):1649-1657.

28. Li XS, Xu Q, Fu XY, Luo WS. Heat shock protein 22 overexpression is associated with the progression and prognosis in gastric cancer. $J$ Cancer Res Clin Oncol. 2014;140(8):1305-1313.

29. Nakajima M, Kato H, Miyazaki T, et al. Tumor immune systems in esophageal cancer with special reference to heat-shock protein 70 and humoral immunity. Anticancer Res. 2009;29(5):1595-1606.

30. Tsiaousidou A, Lambropoulou M, Chatzitheoklitos E, et al. B7H4, HSP27 and DJ-1 molecular markers as prognostic factors in pancreatic cancer. Pancreatology. 2013;13(6):564-569.

31. Liu M, Miao N, Li J, et al. Correlation of HSP70, P53 and Bmi-1 in hepatitis, cirrhosis and hepatocellular carcinoma. Int J Clin Exp Pathol. 2016;9(2):473-480.

32. Chen Y, Chen C, Ma C, Sun S, Zhang J, Sun Y. Expression of heatshock protein gp96 in gallbladder cancer and its prognostic clinical significance. Int J Clin Exp Pathol. 2015;8(2):1946-1953.

33. Schäfer C, Seeliger H, Bader DC, et al. Heat shock protein 27 as a prognostic and predictive biomarker in pancreatic ductal adenocarcinoma. J Cell Mol Med. 2012;16(8):1776-1791. 
34. Zhai LL, Xie Q, Zhou CH, Huang DW, Tang ZG, Ju TF. Overexpressed HSPA2 correlates with tumor angiogenesis and unfavorable prognosis in pancreatic carcinoma. Pancreatology. 2017;17(3): 457-463.

35. King KL, Li AF, Chau GY, et al. Prognostic significance of heat shock protein-27 expression in hepatocellular carcinoma and its relation to histologic grading and survival. Cancer. 2000;88(11):2464-2470.

36. Kang GH, Lee BS, Lee ES, Kim SH, Lee HY, Kang DY. Prognostic significance of p53, mTOR, c-Met, IGF-1R, and HSP70 overexpression after the resection of hepatocellular carcinoma. Gut Liver. 2014;8(1): 79-87.

37. Khalil AA, Kabapy NF, Deraz SF, Smith C. Heat shock proteins in oncology: diagnostic biomarkers or therapeutic targets? Biochim Biophys Acta. 2011;1816(2):89-104.

38. Macario AJ, Conway de Macario E. Molecular chaperones: multiple functions, pathologies, and potential applications. Front Biosci. 2007; $12: 2588-2600$

39. Arnold-Schild D, Kleist C, Welschof M, et al. One-step single-chain Fv recombinant antibody-based purification of gp96 for vaccine development. Cancer Res. 2000;60(15):4175-4178.

40. Bagatell R, Whitesell L. Altered Hsp90 function in cancer: a unique therapeutic opportunity. Mol Cancer Ther. 2004;3(8):1021-1030.

41. Bausero MA, Page DT, Osinaga E, Asea A. Surface expression of Hsp25 and Hsp72 differentially regulates tumor growth and metastasis. Tumour Biol. 2004;25(5-6):243-251.

42. Lang SA, Klein D, Moser C, et al. Inhibition of heat shock protein 90 impairs epidermal growth factor-mediated signaling in gastric cancer cells and reduces tumor growth and vascularization in vivo. Mol Cancer Ther. 2007;6(3):1123-1132.
43. Liu H, Lu J, Hua Y, et al. Targeting heat-shock protein 90 with ganetespib for molecularly targeted therapy of gastric cancer. Cell Death Dis. 2015;6:e1595.

44. Ghosh JC, Siegelin MD, Dohi T, Altieri DC. Heat shock protein 60 regulation of the mitochondrial permeability transition pore in tumor cells. Cancer Res. 2010;70(22):8988-8993.

45. Zhang K, Peng Z, Huang X, et al. Phase II trial of adjuvant immunotherapy with autologous tumor-derived Gp96 vaccination in patients with gastric cancer. J Cancer. 2017;8(10):1826-1832.

46. Garrido C, Fromentin A, Bonnotte B, et al. Heat shock protein 27 enhances the tumorigenicity of immunogenic rat colon carcinoma cell clones. Cancer Res. 1998;58(23):5495-5499.

47. Lin SP, Lee YT, Wang JY, et al. Survival of cancer stem cells under hypoxia and serum depletion via decrease in PP2A activity and activation of p38-MAPKAPK2-Hsp27. PLoS One. 2012;7(11):e49605.

48. Hwang TS, Han HS, Choi HK, et al. Differential, stage-dependent expression of Hsp70, Hsp110 and Bcl-2 in colorectal cancer. J Gastroenterol Hepatol. 2003;18(6):690-700.

49. Ohtsuka K, Hata M. Molecular chaperone function of mammalian Hsp70 and Hsp40 - a review. Int J Hyperthermia. 2000;16(3):231-245.

50. Black JD, Rezvani K. Heat shock protein 70 s as potential molecular targets for colon cancer therapeutics. Curr Med Chem. 2016;23(28): 3171-3188.

51. Nagaraju GP, Park W, Wen J, et al. Antiangiogenic effects of ganetespib in colorectal cancer mediated through inhibition of HIF- $1 \alpha$ and STAT-3. Angiogenesis. 2013;16(4):903-917.

52. Nagaraju GP, Wu C, Merchant N, Chen Z, Lesinski GB, El-Rayes BF. Epigenetic effects of inhibition of heat shock protein 90 (HSP90) in human pancreatic and colon cancer. Cancer Lett. 2017;402:110-116.
OncoTargets and Therapy

\section{Publish your work in this journal}

OncoTargets and Therapy is an international, peer-reviewed, open access journal focusing on the pathological basis of all cancers, potential targets for therapy and treatment protocols employed to improve the management of cancer patients. The journal also focuses on the impact of management programs and new therapeutic agents and protocols on

\section{Dovepress}

patient perspectives such as quality of life, adherence and satisfaction. The manuscript management system is completely online and includes a very quick and fair peer-review system, which is all easy to use. Visit http://www.dovepress.com/testimonials.php to read real quotes from published authors. 